\title{
Cytotoxic response of 5-fluorouracil-resistant cells to gene- and cell- directed enzyme/prodrug treatment
}

\author{
Erika Durinikova ${ }^{1} \cdot$ Jana Plava $^{1} \cdot$ Silvia Tyciakova ${ }^{1} \cdot$ Pavel Skvara $^{2} \cdot$ Andrea Vojs Stanova $^{2,3} \cdot$ Zuzana Kozovska $^{1}$. \\ Lucia Kucerova $^{1} \cdot$ Miroslava Matuskova $^{1}$
}

Received: 31 January 2018 / Revised: 25 May 2018 / Accepted: 3 June 2018 / Published online: 21 June 2018

(c) Nature America, Inc., part of Springer Nature 2018

\begin{abstract}
Gene-directed enzyme/prodrug therapy (GDEPT) mediated by mesenchymal stromal cells (MSC) was already approved for clinical study on a progressive disease refractory to standard therapy. In this work, we examined the effect of several GDEPT approaches on chemoresistant cells. First, we derived 5-fluorouracil (5-FU)-resistant variant of human colorectal adenocarcinoma cells HT-29 designated HT-29/EGFP/FUR. Our data show that the upregulation of thymidylate synthase (TS) and downregulation of thymidine phosphorylase (TP), orotate phosphoribosyl transferase (OPRT) and dihydropyrimidine dehydrogenase (DPD) contributed to the 5-FU resistance in cancer cells. Next, we combined the MSC expressing either yeast cytosine deaminase (CD-MSC) or fusion yeast CD::uracil phosphoribosyl transferase (CD::UPRT-MSC) and prodrug 5-fluorocytosine (5-FC) in a cell-mediated GDEPT approach. Bystander cytotoxic effect in the direct co-cultures of the tumor and therapeutic cells mixed in a 5:1 ratio resulted in 55\% and 70\% inhibition of proliferation, respectively. However, the acquired chemoresistance to 5-FU can be overcome by introducing the prodrug-converting transgene into the tumor cells. When the transgene CD::UPRT was expressed in the chemoresistant cells (CD::UPRT-FUR), substantial suicide effect and a $90 \%$ decrease in viability was observed using non-toxic concentration of $62.5 \mu \mathrm{g} / \mathrm{ml} 5$-FC. In summary, we demonstrate here that the transgene introduction circumvented 5-FU resistance in the tumor cells.
\end{abstract}

\section{Introduction}

A large number of preclinical studies highlighted the ability of mesenchymal stromal cells (MSC) to selectively navigate to sites of tumor burden, thus suggesting their roles as intriguing vehicles in improving the delivery of targeted agents [1-5]. Gene-directed enzyme/prodrug therapy

Miroslava Matuskova

miroslava.matuskova@savba.sk

1 Department of Molecular Oncology, Cancer Research Institute, Biomedical Research Center of Slovak Academy of Sciences, Dubravska cesta 9,84505 Bratislava, Slovakia

2 Department of Analytical Chemistry, Faculty of Natural Sciences, Comenius University, Mlynska dolina, Ilkovicova 6, 84215 Bratislava, Slovakia

3 Faculty of Fisheries and Protection of Waters, University of South Bohemia in Ceske Budejovice, South Bohemian Research Center of Aquaculture and Biodiversity of Hydrocenoses, Research Institute of Fish Culture and Hydrobiology, Zatisi 728/II, 38925 Vodnany, Czech Republic
(GDEPT) using therapeutic MSC allows selective conversion of non-toxic compounds (prodrugs) by activating enzymes into cytotoxic drugs in the vicinity of the tumor while minimizing impact on normal tissues. The most widely used approach is represented by thymidine kinase of Herpes simplex virus (HSVtk) in combination with ganciclovir (GCV). Then, either bacterial or yeast cytosine deaminase (CD) alone or fused with uracil phosphoribosyl transferase (CD::UPRT) converts 5-fluorocytosine (5-FC) $[6,7]$. The latter combination was proved highly effective as only $4 \%$ of therapeutic cells expressing CD::UPRT eliminated over $98.5 \%$ of the human melanoma A375 cells in vitro [8]. The advantage of GDEPT is the spread of cytotoxicity from the originally transduced cells to neighboring neoplastic, non-transduced cells, an effect known as bystander cytotoxic effect. Thus, therapeutic MSC release toxic metabolites affecting surrounding tumor cells $[6,9]$. The ability of transduced cells to kill themselves by produced toxic metabolites (converted prodrug) - the so-called suicide effect-causes elimination of themselves, which means that their presence is not permanent in the tumor, thus predetermine MSC to become valuable vehicles for the 
delivery of various "suicide" transgenes to target tumor [10]. The CD::UPRT-MSC/5-FC regimen inhibited tumor growth in many models of cancer-colon carcinoma [11], prostate cancer [4], melanoma [8, 12], medullary thyroid carcinoma [13], glioblastoma [5, 14, 15] including ovarian metastatic disease [16]. On the other hand, we demonstrated that particular human tumor cell lines differ in their response to CD::UPRT-MSC/5-FC system, and we identified specific factors influencing this response-expression level of enzymes of nucleotide metabolism, functional gapjunctional intercellular communication (GJIC) between cells and expression of ATP-binding cassette transporters [17]. The major determinants that should be considered for the application of the prodrug-activating MSC in antitumor therapy in order to maximize therapeutic efficiency have been summarized [18]. Refractoriness to the given regimen can be overcome by combination of the systems, and synergy by double-prodrug enzyme-directed gene therapy was demonstrated depending on tested cell lines and experimental setup. Systemic administration of CD::UPRTMSC and HSV tk-MSC in combination with 5-FC and GCV cleared the breast cancer cells from the lungs in a lung colonization assay [19].

Despite significant success of GDEPT approach at the preclinical level, there is still much work ahead to find out to what extent genetically modified MSC are able to target aggressive chemoresistant subpopulations of tumor cells. Yet, no study evaluating the ability of GDEPT approaches to induce cytotoxic effect in chemoresistant colorectal carcinoma cells and overcome refractoriness to standard treatment has been conducted. Thus, we examined the efficiency of cell vehicle-mediated regimen $\mathrm{CD}(: \because \mathrm{UPRT})$ MSC/5-FC as well as direct transgene introduction in the gene/prodrug approach CD::UPRT/5-FC on the model of chemoresistant cell line HT-29/EGFP/FUR derived from a chemosensitive parental colorectal adenocarcinoma HT-29 cells.

\section{Materials and methods}

\section{Cells}

Human colon adenocarcinoma cell line HT-29 (ECACC no. 91072201) and breast cancer cell line T47D (ATCC ${ }^{\circ}$ HTB$\left.133^{\mathrm{TM}}\right)$ were maintained in high-glucose $(4.5 \mathrm{~g} / \mathrm{l})$ Dulbecco's modified Eagle medium (DMEM; PAN Biotech, Germany) supplemented with $10 \%$ fetal calf serum (FCS; Biochrom AG, Germany), $2 \mathrm{mM}$ glutamine (PAA Laboratories $\mathrm{GmbH}$, Austria), or GlutaMAX (Gibco by Life Technologies, USA), and antibiotics $10 \mu \mathrm{g} / \mathrm{ml}$ gentamicin (Sandoz, Germany) and $2.5 \mu \mathrm{g} / \mathrm{ml}$ amphotericin B (SigmaAldrich, USA). Adipose tissue-derived MSCs were isolated from lipoaspirate or adipose tissue obtained from healthy individuals undergoing liposuction or plastic surgery after their informed consent. The procedure was approved by the Ethics Committee of the University Hospital (Ruzinov, Ruzinovska 6, 82606 Bratislava, Slovakia). MSCs were isolated by plastic adherence technique and characterized by the immunophenotype and differentiation potential as previously described [1], and were cultivated in low-glucose $(1 \mathrm{~g} / \mathrm{l})$ DMEM containing 10\% FCS, GlutaMAX, and antibiotic-antimycotic mix. Four batches of isolated MSC from different donors were prepared for experiments to exclude the variability among individuals. Packaging cells $\mathrm{GP}+\mathrm{E}-86$ (ATCC ${ }^{\circ}$-CRL-9642 ${ }^{\mathrm{TM}}$ ) and $\mathrm{GP}+$ envAM12 $\left(\right.$ ATCC $^{\circ}$-CRL-9641 ${ }^{\mathrm{TM}}$ ) were maintained in high-glucose DMEM supplemented with 5\% FCS, GlutaMAX, and antibiotic-antimycotic mix. Cells were tested for mycoplasma contamination based on internal laboratory rules by PCR.

\section{Preparation of chemoresistant derivative of HT-29/ EGFP cells}

HT-29/EGFP cell line (prepared as stated below) has been gradually exposed to 5-FU (Sigma-Aldrich) according to ref. [20], and finally, chemoresistant cells referred to as HT29/EGFP/FUR stably proliferating in plasma concentration of 5 -FU $(2 \mu \mathrm{g} / \mathrm{ml})$ were prepared. These cells were maintained in high-glucose DMEM supplemented with $10 \%$ FCS, antibiotic-antimycotic mix, and $2 \mu \mathrm{g} / \mathrm{ml}$ of 5-FU. Cells that have undergone serial passages were used for experiments-cells till 20th passage are referred to as HT-29/ EGFP/FUR "low", 21-40th passage are "middle", and cells after 40th passage were named "high."

\section{Constructs used for genetic modification}

Genetic modifications of cells were performed by stable transduction with MLV (murine leukemia virus)-derived retroviral vectors based on plasmid pJZ308 [9], or by IncuCyte $^{\mathrm{TM}}$ NucLight $^{\mathrm{TM}}$ Red Lentivirus reagent (Essen Bioscience, UK).

Retroviral vectors encoding gene for enhanced green fluorescent protein (pEGFP vector) and synthetic fusion yeast CD::UPRT gene (pST2 vector) were used according to our previous studies [1, 17]. Vector pST1 was constructed by insertion of single intronless yeast $\mathrm{CD}$ gene originated from pORF5-Fcy plasmid (InvivoGen, USA) into the pJZ308 backbone. Vector pST2puro is a modification of pST2 plasmid, where the selection marker gene for neomycin resistance was replaced by gene for puromycin resistance ( $N$-acetyl-transferase gene). The puromycin resistance gene was excised from the pBABEpuro vector (CellBiolabs, USA). Preparation of stable virus- 
producing packaging cell lines and production of retroviruscontaining supernatants was performed as stated in ref. [1].

\section{Transduction of cells}

HT-29 cells were genetically modified to stably express EGFP gene as stated in ref. [17]. Therapeutic MSC expressing CD (referred to as CD-MSC) or fusion CD:: UPRT (referred to as CD::UPRT-MSC) were prepared according to [11, 21]. For HPLC analysis, MSC were transduced with two types of retroviral vectors-either ST1 or ST2 at multiplicity of infection (MOI) of 100 according to refs. [11, 21]. HT-29/EGFP/FUR cells expressing the $C D:: U P R T$ gene (referred to as CD::UPRT-FUR) were prepared by transduction of HT-29/EGFP/FUR "high" by ST2puro retroviral vector as stated above. For kinetic measurements, we prepared HT-29/EGFP and HT-29/ EGFP/FUR "high" cells expressing a nuclear red fluorescent protein using IncuCyte ${ }^{\mathrm{TM}}$ NucLight $^{\mathrm{TM}}$ Red Lentivirus Reagent with puromycin resistance. We used MOI of 6 and proceeded according to manufacturer's protocol (Essen BioScience). Cells are referred to as HT-29/NLR and FUR/NLR, respectively.

\section{Evaluation of gap-junctional intercellular communication}

GJIC of tumor cells with MSC was detected by fluorescent dye transfer assay, and evaluated by flow cytometry as described previously [19].

\section{Cell viability assays}

In the co-culture experiments, $2 \times 10^{3}$ tumor cells and therapeutic MSC were mixed at a ratio of 5:1 seeded in 96well plates, plated to let adhere overnight. Next day, the culture medium was supplemented with concentration gradient of 5-FC ranging from 16 to $1000 \mu \mathrm{g} / \mathrm{ml}$ (SigmaAldrich, USA) and cultured for 6 days. CellTiter-Glo ${ }^{\circ}$ Luminescent Cell Viability Assay (Promega, USA) was performed according to manufacturer's instructions. The results were expressed as percentage of relative viability, and evaluated as in ref. [16]. Values were expressed as means of replicates $\pm \mathrm{SD}$, when luminescence of control cells without the prodrug was taken as reference. Experiments were repeated at least thrice with similar results, and a representative result is shown. The $\mathrm{IC}_{50}$ values were counted using CalcuSyn program.

For pharmacological inhibition of enzymes involved in 5-FC and 5-FU metabolism, $4 \times 10^{3}$ HT-29/EGFP tumor cells were seeded in 96-well plates with 24-h-long pretreatment with non-toxic concentration of either 5-chloro-6(1-(2-iminopyrrolidinyl)methyl) uracil hydrochloride (TPI, a TP inhibitor at a concentration of $1.5 \mathrm{ng} / \mathrm{ml}$ ) or gimeracil (GIM at a concentration of $0.6 \mathrm{nM}$; Sigma-Aldrich). Twenty-four hours later, 5-FU at indicated concentrations of 0.125 and $0.25 \mu \mathrm{g} / \mathrm{ml}$ with or without inhibitors was added to cells for 5 days. Relative viability was determined by luminescence viability assay as stated above.

For 5-FC and 5-FU sensitivity determination, replicates of HT-29/EGFP/FUR and CD::UPRT-FUR cells (prepared as stated above) were seeded in 96-well plates at a density of 3500 cells per well $24 \mathrm{~h}$ prior treatment. Medium was then supplemented with either 5-FC (at concentrations ranging from 16 to $1000 \mu \mathrm{g} / \mathrm{ml}$ ) or 5 -FU (at concentrations ranging from 0.25 to $40 \mu \mathrm{g} / \mathrm{ml}$ ), and cells were treated for 5 days. Relative viability at experimental end point was determined by luminescent cell viability assay as stated above.

\section{Kinetic evaluation of proliferation and cytotoxic effect}

Kinetic measurements were based on counting of red nuclei of tumor cells (HT-29/NLR and FUR/NLR) in direct cocultures with CD::UPRT-MSC (5:1 ratio; $2 \times 10^{3}+4 \times 10^{2}$ seeded in 96-well plates) by IncuCyte $\mathrm{ZOOM}^{\mathrm{TM}}$ kinetic imaging system evaluated by IncuCyte ZOOM $^{\mathrm{TM}}$ software 2016A (Essen BioScience). Twenty-four hours after seeding, cells were co-cultured in the presence of 5-FC at a concentration of $500 \mu \mathrm{g} / \mathrm{ml}$ for 6 days. Number of NLR cells in the co-culture without 5-FC at a given time point was taken as $100 \%$. Values were expressed as means of replicates $\pm \mathrm{SD}$.

Cytotoxicity of 5-FU at concentrations ranging from 0.01 to $100 \mu \mathrm{g} / \mathrm{ml}$ was detected by culture of HT-29/NLR and FUR/NLR cells $\left(3 \times 10^{3}\right.$ cells per 96 -well plate $)$ after 5 -FU addition $24 \mathrm{~h}$ after plating for 6 days. Number of NLR cells in the culture without 5-FU at a given time point was taken as $100 \%$. Values were expressed as means of replicates \pm SD.

To detect the sensitivity of tumor cells to raltitrexed monohydrate (Tomudex, a TS inhibitor; AstraZeneca, UK) at concentrations ranging from 0.03 to $100 \mathrm{nM}, 3 \times 10^{3}$ cells per 96-well plate were plated with raltitrexed addition $24 \mathrm{~h}$ after seeding and incubated for 7 days. Cell confluence expressed as relative proliferation was evaluated by kinetic imaging system based on processing definitions and confluence mask appropriate for HT-29/EGFP and HT-29/ EGFP/FUR cells. Data were expressed as means of replicates \pm SD.

For evaluation of proliferation rate of HT-29/NLR and FUR/NLR cells under standard culture conditions, $3 \times 10^{3}$ cells were seeded in 96-well plates, let to adhere, and kinetic imaging scanning with enumeration of red nuclei was performed for 6 days. Values were expressed as means of replicates $\pm \mathrm{SD}$. 
Table 1 Sequences of primers used for expression analysis

\begin{tabular}{llll}
\hline Gene & Product size & Forward primer $\left(5^{\prime}-3^{\prime}\right)$ & Reverse primer $\left(5^{\prime}-3^{\prime}\right)$ \\
\hline HPRT1 & $137 \mathrm{bp}$ & TGACCAGTCAACAGGGGACA & ACTGCCTGACCAAGGAAAGC \\
GAPDH & $226 \mathrm{bp}$ & GAAGGTGAAGGTCGGAGTC & GAAGATGGTGATGGGATTTC \\
$C x 43$ & $72 \mathrm{bp}$ & TCAATCACTTGGCGTGACTTC & GCGCTCCAGTCACCCATGT \\
DPD & $237 \mathrm{bp}$ & GTTGTGGCTATGATTGATGA & ATTCACAGATAAGGGTACGC \\
OPRT & $146 \mathrm{bp}$ & GCTTGGGAAGCGTATTTGAG & GTGGAAGAATCCAAGCAGGA \\
TS & $144 \mathrm{bp}$ & ACCTGAATCACATCGAGCCA & TTGGATGCGGATTGTACCCT \\
TP & $238 \mathrm{bp}$ & CGCCTGGTGACTTCTCC & TGGGTCAGCACCGAGGT \\
\hline
\end{tabular}

To detect the sensitivity of FUR/NLR cells to 5 -FU at coculture experiment with CD::UPRT-MSC, $5 \times 10^{3}$ tumor cells with $1 \times 10^{3}$ transduced MSC were seeded in 96-well plates. One day later, 5-FU at indicated concentrations of 5 and $10 \mu \mathrm{g} / \mathrm{ml}$ was added. Red nuclei count of tumor cells was evaluated by kinetic imaging system for 6 days. Values were expressed as means of replicates $\pm \mathrm{SD}$.

\section{Three-dimensional multicellular aggregate models}

The 3D aggregate co-culture of $3 \times 10^{3}$ tumor cells mixed with CD::UPRT-MSC (labeled with DiI) at a ratio of 5:1 (at least sextaplicates) were plated in ultra-low attachment $\mathrm{U}$ bottom 96-well plates (Corning 7007; Corning, USA) according to ref. [16]. Seventy-two hours after plating, when the aggregates were visible and tightly formed, the medium was supplemented with concentrations gradient of 5-FC ranging from 10 to $1000 \mu \mathrm{g} / \mathrm{ml}$. At the assay end point 7 days after 5-FC adding, plates were subjected to the viability luminescent assay as described above.

\section{Bystander effect analysis}

In an independent experiment, HT-29/EGFP/FUR and CD:: UPRT-FUR (prepared as stated above) were mixed at indicated ratios, plated 3500 cells per well in 96-well plate and let to adhere for $24 \mathrm{~h}$. Then treatment with $250 \mu \mathrm{g} / \mathrm{ml}$ 5-FC started with luminescence viability evaluation 5 days later as described above. Viability of cells without 5-FC prodrug was set as $100 \%$. Values were expressed as means of replicates $\pm \mathrm{SD}$.

\section{Expression analysis}

Total RNA was isolated from $1-2 \times 10^{6}$ tumor cells by NucleoSpin ${ }^{\oplus}$ RNA II Mini Total RNA Isolation Kit (Macherey Nagel, Germany) according to the protocol. Isolated RNA was reverse-transcribed with RevertAid ${ }^{\mathrm{TM}} \mathrm{H}$ minus First Strand cDNA Synthesis Kit (Thermo Scientific, USA). Quantitative PCR was performed in $1 \times$ GoTaq $^{\circledR}$ qPCR Master Mix (Promega, USA) with specific primers (10 pmol/ $\mu \mathrm{l}$ ) (summarized in Table 1 ) and $1 \mu \mathrm{l}$ of template
cDNA on Bio-Rad CFX96 ${ }^{\mathrm{TM}}$ Real-Time PCR Detection System (Bio-Rad, USA) using the following protocol: activation step at $95^{\circ} \mathrm{C}$ for $2 \mathrm{~min}, 40$ cycles of denaturation at $95^{\circ} \mathrm{C}$ for $15 \mathrm{~s}, 1 \mathrm{~min}$ annealing and polymerization at 60 ${ }^{\circ} \mathrm{C}$ with plate read for $5 \mathrm{~s}$ at $76^{\circ} \mathrm{C}$ followed by denaturation at $95^{\circ} \mathrm{C}$ for $10 \mathrm{~s}$, and final extension for $5 \mathrm{~s}$ at $65^{\circ} \mathrm{C}$. Obtained data were subsequently analyzed using CFX Manager ${ }^{\mathrm{TM}}$ Software (Version 1.5; Bio-Rad). Gene expression was calculated using delta cycle threshold values $\left(\Delta \mathrm{Ct}=\mathrm{Ct}_{\text {TARGET GENE }}-\mathrm{Ct}_{\text {REFERENCE GENE }}\right)$. The expression of HPRT1 and GAPDH genes was set as an endogenous reference. Analysis was performed in triplicates and data were expressed as means $\pm \mathrm{SD}$.

\section{High-performance liquid chromatography-mass spectrometry analysis}

In order to define the conversion of 5-FC and quantification of released metabolites to culture medium, we performed high-performance liquid chromatography-mass spectrometry (HPLC-MS) analysis of culture supernatants of CDor CD::UPRT-transduced cells. On the first day, either 450,000 of CD::UPRT-FUR tumor cells or $300,000 \mathrm{CD}$ - or CD::UPRT-MSC were seeded on six-well plates with standard culture medium. Three days later, fresh medium with/without 5 -FC $(1000 \mu \mathrm{g} / \mathrm{ml})$ was added. In $48 \mathrm{~h}$, supernatants were collected, centrifuged (3000 r.p.m., $10 \mathrm{~min}$ ), and filtered through $0.2 \mu \mathrm{m}$ filters. Proteins were subsequently removed by ultrafiltration through Amicon Ultra Filters (Merck Millipore, USA)—100 kDa type (4300 r.p.m., $14 \mathrm{~min}$ ), then $30 \mathrm{kDa}$ type (4300 r.p.m., $40 \mathrm{~min}$ ). Filtered culture media were then kept frozen at $-80^{\circ} \mathrm{C}$. The HPLC-MS analysis was performed by combination of highperformance liquid chromatography with high-resolution mass spectrometry (HPLC-MS-IT-TOFTM; Shimadzu, Japan). The used mass spectrometer combines the electrospray ionization, ion trap (IT), and time-of-flight (TOF) mass analyzer, which enables to perform $\mathrm{MS}^{n}$ experiments with high mass accuracy and precision.

Chromatographic separations were performed on Ascentis C18 column $(100 \times 2.1 \mathrm{~mm} ; 3 \mu \mathrm{m}$ particles $)$ (Sigma-Aldrich), with the column temperature set to $40^{\circ} \mathrm{C}$. 


\section{A HT-29/EGFP}

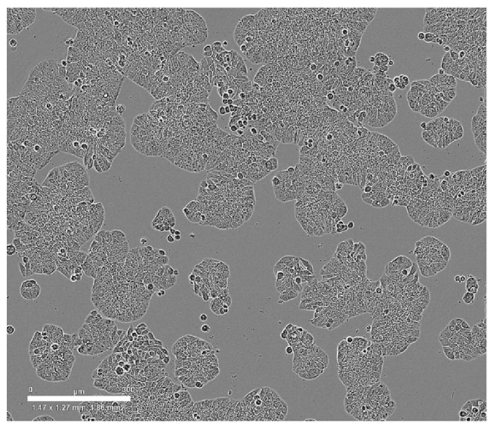

B

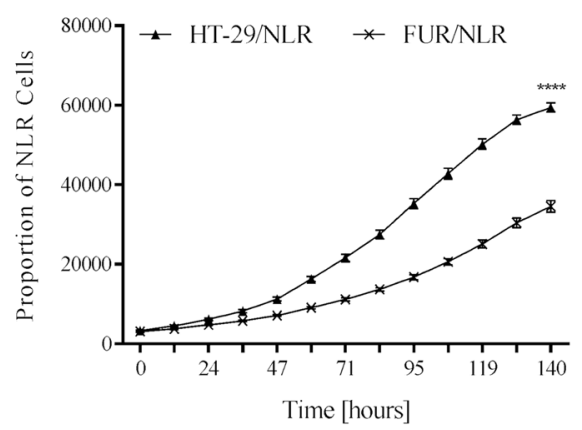

HT-29/EGFP/FUR

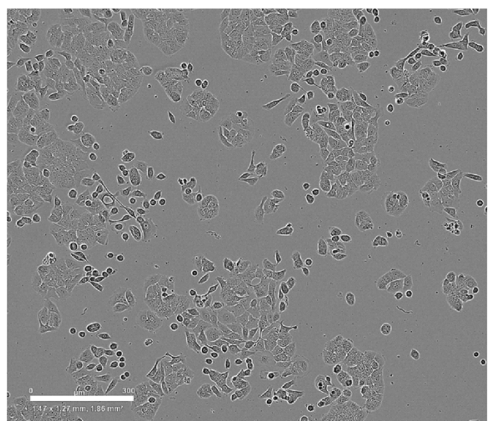

C

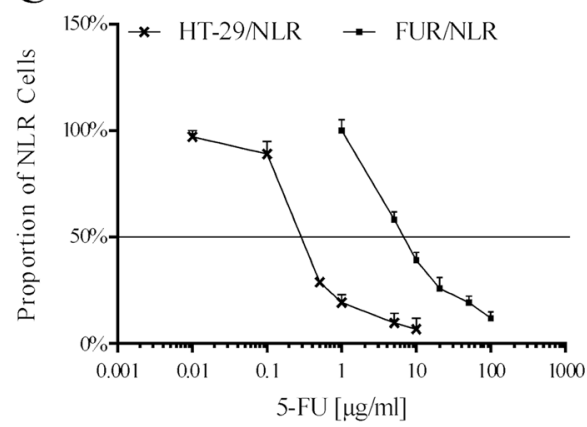

D

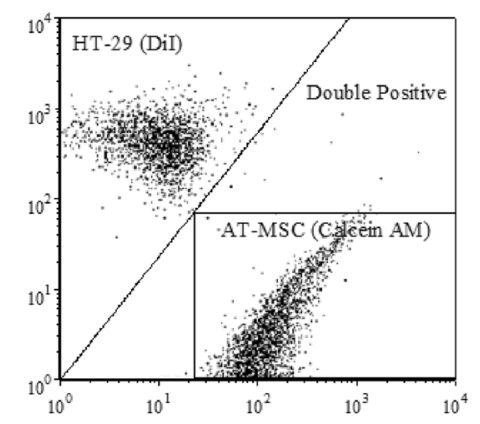

E

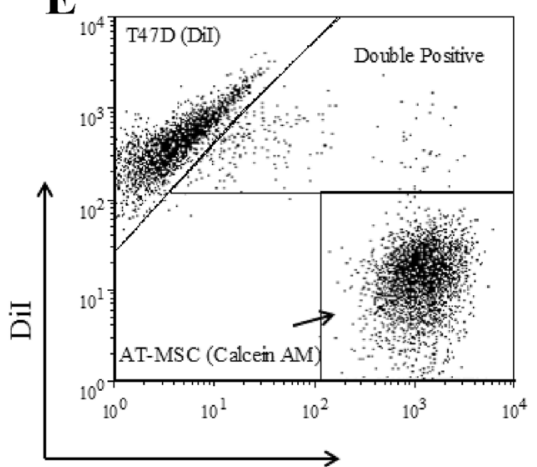

Calcein AM
24 hrs Coculture
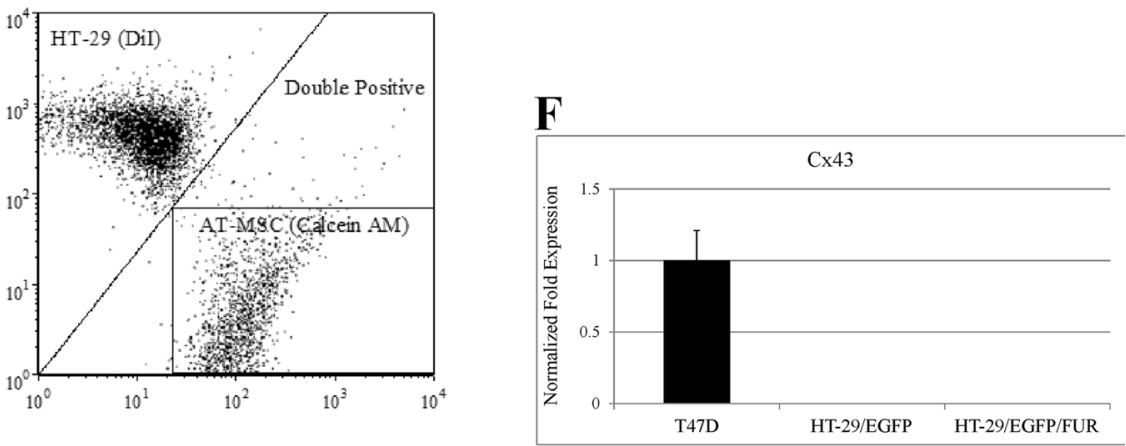

A gradient elution of $10 \mathrm{mmol} / \mathrm{L}$ formic acid: acetonitrile $(10: 90 \%, v / v)$ was used. The mobile phase flow rate was $0,2 \mathrm{ml} / \mathrm{min}$ and injected volume was $5 \mu \mathrm{l}$. The MS conditions were as follows: electrospray capillary voltage was
$+4.5 \mathrm{kV}$ and $-3.5 \mathrm{kV}$ in the positive and negative ionization mode, respectively. The drying gas flow rate was $10 \mathrm{~L} / \mathrm{min}$; drying gas temperature was $200{ }^{\circ} \mathrm{C}$. MS data was collected in the $m / z$ range of $100-400$. The $\mathrm{MS}^{2}-\mathrm{MS}^{4}$ spectra were 
Fig. 1 Derivative HT-29/EGFP/FUR cell line prepared from human HT-29 cells is chemoresistant and incapable to communicate with the MSC via gap-junctional intercellular communication . We prepared chemoresistant cell line HT-29/EGFP/FUR by stable exposure of initially chemonaive HT-29/EGFP cells to increasing concentrations of the 5-FU till stable propagation in $2 \mu \mathrm{g} / \mathrm{ml}$. Chemonaive HT-29/EGFP cells and their resistant derivative HT-29/EGFP/FUR were used for this study (a). b Direct enumeration of the red nuclei of the tumor cells by the kinetic imaging system showed significantly decreased proliferation rate of chemoresistant cells (here referred to as FUR/NLR) with 1.7-fold less cells presented in the culture after 140-h-long cultivation under the standard culture conditions. Values were expressed as means of decaplicates \pm SD. Mann-Whitney $U$-test was used for statistical analysis. $* * * * p<0.0001$. c Prolonged treatment of tumor cells with the 5-FU did increase the resistance of FUR/NLR cells as evaluated by direct counting of the tumor cell nuclei after 6-day-long exposure to 5-FU concentration gradient. Values were expressed as means of sextaplicates \pm SD. d For the detection of gap-junctional intercellular communication, tumor cells were stained with DiI, adipose tissue-derived MSC (AT-MSC) were stained with calcein AM. HT-29 cells and MSCs were mixed immediately before measurement (fresh mix), as well as co-cultured for $24 \mathrm{~h}$. We did not observe double-positive tumor cells indicating calcein AM transfer via gap junctions during co-culture. e Human breast cancer cell line T47D was used as a positive control. $\mathbf{f}$ The expression of $\mathrm{Cx} 43$ was determined by qPCR in the HT-29/EGFP and HT-29/EGFP/FUR cells. T47D cells were used as a positive control, HPRT1 served as an internal control

obtained by fragmentation of molecular ion of each analytes. The total time of HPLC-MS analysis was $12 \mathrm{~min}$. Data acquisition and processing were performed using software LC-MS Solutions v. 3.81.418.

\section{In vivo experiments}

Animal experiments were approved by the Institutional Ethic Committee and by the national competence authority - State Veterinary and Food Administration of the Slovak Republic (project registration no. Ro 2807/12-221) in compliance with the Directive 2010/63/EU and the Regulation 377/2012 on the protection of animals used for scientific purposes. Project was conducted in the approved animal facility (license no. SK PC 14011). Six- to eightweek-old SCID/bg mice $(n=4)$ were bilaterally s.c. injected by $2 \times 10^{6}$ HT-29/EGFP/FUR "low" cells resuspended in $150 \mu \mathrm{l}$ serum-free DMEM diluted 1:1 with extracellular matrix (ECM) gel (Sigma-Aldrich). Prior to injection, the viability of tumor cells was proved by Trypan Blue staining (Life Technologies). Animals were regularly inspected for the tumor incidence and considered tumor-free when no palpable rigid structure could be detected. At the experimental end point (5 months after injection), one xenograft was mechanically dissociated into small pieces and seeded in culture medium for tumor cell expansion. Isolated cells were then selected based on G418 resistance. This in vivoderived cell line (hereafter referred to as FURiv) was established and used for subsequent experiments.

\section{Statistical analysis}

All experiments were performed at least thrice, and representative results is shown. Data involving comparison between two groups were analyzed by either unpaired Student's $t$-test or non-parametric Mann-Whitney $U$-test. Comparison of more than two groups was analyzed by either parametric ANOVA with Bonferroni's or Tamhanes's tests depending on homogeneity of variance for multiple comparisons or non-parametric Kruskal-Wallis test. The data were analyzed by GraphPad Prism ${ }^{\circ}$ software (LA Jolla, USA) and SPSS Statistics 23.0 (IBM, USA). The value of $p<0.05$ was considered statistically significant.

\section{Results}

In order to examine the capability of prodrug-converting MSC to overcome acquired chemoresistance in tumor cells, we derived chemoresistant HT-29/EGFP/FUR cells by long-term culturing of chemonaive HT-29 in elevating concentrations of 5-FU. This derivative was designated as chemoresistant after stable maintenance in patients' plasma concentration of 5-FU $(2 \mu \mathrm{g} / \mathrm{ml})$. Chemoresistant cells HT29/EGFP/FUR differ in their morphology (Fig. 1a) and have longer population doubling time of $\sim 39 \mathrm{~h}$ in comparison to $\sim 26 \mathrm{~h}$ of HT-29 cells. Both tumor cell lines were stained with the red nuclear protein (NLR) in order to enable kinetic measurements in the kinetic imaging system, and were labeled as HT-29/NLR and FUR/NLR. Based on the calculation of red nuclei in the culture under standard culture conditions, we observed decreased in vitro proliferation rate of chemoresistant cells-1.7-fold decreased number of FUR/NLR cells in the culture when compared to the number of HT-29/FUR cells (Fig. 1b). We evaluated how the exposure of the cells to the 5-FU changed the sensitivity to this drug based on quantification of live cells (proportion of NLR cells). Prolonged treatment with 5-FU increased the resistance of tumor cells significantly. At high concentration of 5-FU of $10 \mu \mathrm{g} / \mathrm{ml}, 93 \%$ of HT-29/NLR cells were dead in comparison to $60 \%$ of HT-29/EGFP/FUR (Fig. 1c). Thus, we prepared 5-fluorouracil-resistant derivative for subsequent experiments determining the potential of GDEPT approaches to eliminate these cells.

The HSVtk/GCV regimen relies on functional GJIC [17, 21]. A dye transfer assay demonstrated that chemonaive HT-29 (stained with DiI dye) and MSC cells (stained with calcein $\mathrm{AM}$ ) did not form functional gap junctions during co-culture (Fig. 1d). As a positive control, we used breast cancer cell line T47D, which is capable of communication with MSC via gap junctions (Fig. 1e). Additionally, neither HT-29 nor HT-29/EGFP/FUR cells express Cx43, the most 
widely expressed membrane connexin protein, as detected by qPCR (Fig. 1f). Based on these results, we concluded that the HSVtk/GCV regimen was not suitable to eliminate HT-29-derived cells by bystander toxicity.

Based on these findings, we performed a gene therapy approach independent of gap junction formation such as combination of yeast cytosine deaminase $\mathrm{CD}$ and its fusion variant CD::UPRT combined with 5-FC prodrug in order to test suicide and bystander cytotoxic effect on HT-29/EGFP/ FUR cells. Initially, we had published high antitumor efficiency of this combination on HT-29 cells along with significant tumor growth inhibition in vivo [11]. Direct comparison of the sensitivity between parental HT-29 and resistant cells HT-29/EGFP/FUR revealed shift in IC $_{50}$ values in the HT-29/EGFP/FUR cells in low passage. We detected an $\mathrm{IC}_{50 / 5-\mathrm{FC}}$ of $3.1 \mu \mathrm{g} / \mathrm{ml}$ for HT-29/EGFP cells in comparison to $133.2 \mu \mathrm{g} / \mathrm{ml}$ for HT-29/EGFP/FUR lowpassaged cells on the sixth day after the treatment started, which makes them 43-fold more resistant. The resistance to given regimen increased along with increasing passage number and the time while the resistant cells were propagated in 5-FU. Detected $\mathrm{IC}_{50}$ values further increased in middle-passaged HT-29/EGFP/FUR cells $\left(\mathrm{IC}_{50 / 5-\mathrm{FC}}\right.$ of $450.3 \mu \mathrm{g} / \mathrm{ml}$ ). As depicted on the graph, we did not reach $50 \%$ viability decrease in HT-29/EGFP/FUR cells in high passage (calculated $\mathrm{IC}_{50 / 5-\mathrm{FC}}=1015.8 \mu \mathrm{g} / \mathrm{ml}$ ) (Fig. 2a). Representative images of chemoresistant cells expressing the red nuclear protein in the direct co-culture with $\mathrm{CD}:$ : UPRT-MSC in the presence of 5-FC of $500 \mu \mathrm{g} / \mathrm{ml}$ for 6 days depict their capability to withstand the bystander cytotoxicity exerted by the therapeutic cells (Fig. 2b). Direct enumeration of the tumor cells present in the co-cultures after the treatment on day 6 exhibited reduction by $67 \%$ in comparison to $91 \%$ reduction in HT-29/EGFP (Fig. 2c).

In order to verify these findings, we examined the effect of CD::UPRT-MSC/5-FC in a 3D co-culture model, as it was previously described to be suitable for prediction of therapeutic outcome [16, 22]. Significant decrease in the 3D aggregate volume of HT-29/EGFP and therapeutic MSC was observed when treated with $5-\mathrm{FC}$ in concentration gradient ranging from 10 to $1000 \mu \mathrm{g} / \mathrm{ml}$. The lowest 5-FC concentration of $10 \mu \mathrm{g} / \mathrm{ml}$ already induced the cytotoxic effect in 44\% of HT-29/EGFP cells and only in 25\% of HT29/EGFP/FUR cells. On the other hand, we did not observe significant shrinkage of aggregates composed of HT-29/ EGFP/FUR cells and therapeutic MSC. Regardless the increase of 5-FC concentration 50-fold, the viability of HT29/EGFP/FUR cells remained unchanged compared to the lowest concentration used, thus increasing the 5-FC concentrations to toxic levels show no advantage in chemoresistant cells' killing. The viability measurements at the experiment end point showed 97\% reduction in HT-29/ EGFP aggregates' viability (with $500 \mu \mathrm{g} / \mathrm{ml}$ 5-FC) in comparison to only $30 \%$ reduction in the case of chemoresistant cells (Fig. 2d).

Based on the in vitro data, where we were able to show that regimen CD::UPRT-MSC/5-FC mediated partial inhibition of tumor cells' viability in both adherent and 3D cocultures, we aimed to examine the potential of the therapy to control tumor growth in vivo. We injected two millions of HT-29/EGFP/FUR cells subcutaneously in SCID/bg mice to produce growing xenografts. In contrast to parental cells, HT-29/EGFP/FUR did not form s.c. tumors. Thus, based on very low tumorigenicity of chemoresistant cells, we did not manage to proceed to in vivo testing of the efficiency of therapeutic MSC. Only one xenograft (1 out of 8 injected) developed-but not exceeding volume of $40 \mathrm{~mm}^{3}$ during 5 months, and this xenograft was used for subsequent in vitro expansion of the tumor cells. Derived established cell line (referred to as FURiv) was examined for the sensitivity to the CD::UPRT-MSC/5-FC in vitro by the luminescent viability assay in adherent co-culture. FURiv cells retained their resistance to the treatment even after 5-monthlong in vivo growth, and subsequent 2-month-long cultivation in vitro without the 5 -FU selection pressure. The sensitivity of FURiv cells to CD::UPRT-MSC/5-FC was the same as for HT-29/EGFP/FUR cells from which the xenograft and subsequent FURiv cells had been established (Fig. 2e).

Next, we wanted to exclude the possibility, that the refractoriness of the HT-29/EGFP/FUR cells to the CD:: UPRT-MSC/5-FC-mediated bystander effect was associated with the inability of therapeutic cells to provide toxic metabolites of converted 5-FC to target the chemoresistant cells. The UPRT domain of fusion CD::UPRT enzyme converts 5-FU to charged molecule 5-fluorouridine monophosphate (5-FUMP), which is not released or taken up by passive diffusion. We hypothesized, that the MSC expressing single yeast cytosine deaminase (CD-MSC) would produce freely diffusing 5-FU preferentially, thus potentially exerting more potent bystander effect in HT-29/EGFP/FUR cells. Based on this hypothesis, we tested the extent of the cytotoxicity mediated by alternative treatment regimen CD-MSC/5-FC. Again, we observed low efficacy on HT-29/EGFP/FUR cells after co-culture in the presence of high concentration of 5-FC $(1000 \mu \mathrm{g} / \mathrm{ml})$ for 6 days. We detected the decrease in viability for $55 \%$ of chemoresistant cells in comparison to $82 \%$ of parental HT29/EGFP cells - the bystander cytotoxic effect was even lower compared to MSC expressing CD::UPRT (Fig. 3a).

Kinetic evaluation of co-cultures based on the red nuclei count of the tumor cells revealed that the presence of UPRT domain does not play an important role in the extent of bystander effect mediated by therapeutic MSC on HT-29/ EGFP cells (Fig. 3b). On the other hand, we observed significant difference in bystander toxicity between CD- 


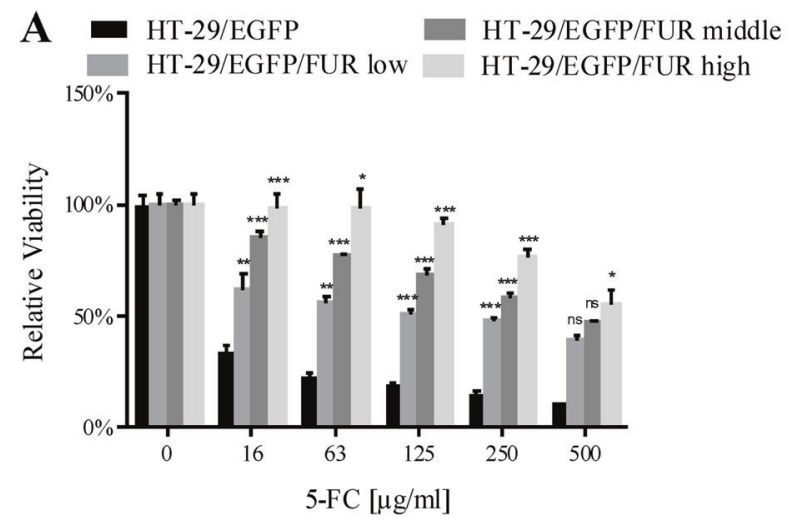

\begin{tabular}{|c|c|}
\hline & $\mathrm{IC}_{50} 5$-FC $[\mu \mathrm{g} / \mathrm{ml}]$ \\
\hline HT-29/EGFP & $\begin{array}{c}3.1(2.5-3.7) \\
\mathrm{r}=0.99\end{array}$ \\
\hline HT-29/EGFP/FUR low & $\begin{array}{c}133.2(103.9-170.8) \\
\mathrm{r}=0.98\end{array}$ \\
\hline HT-29/EGFP/FUR middle & $\begin{array}{c}450.3(349.04-580.8) \\
\mathrm{r}=0.99\end{array}$ \\
\hline HT-29/EGFP/FUR high & $\begin{array}{c}1015.8 \\
\text { (calculated value) }\end{array}$ \\
\hline
\end{tabular}
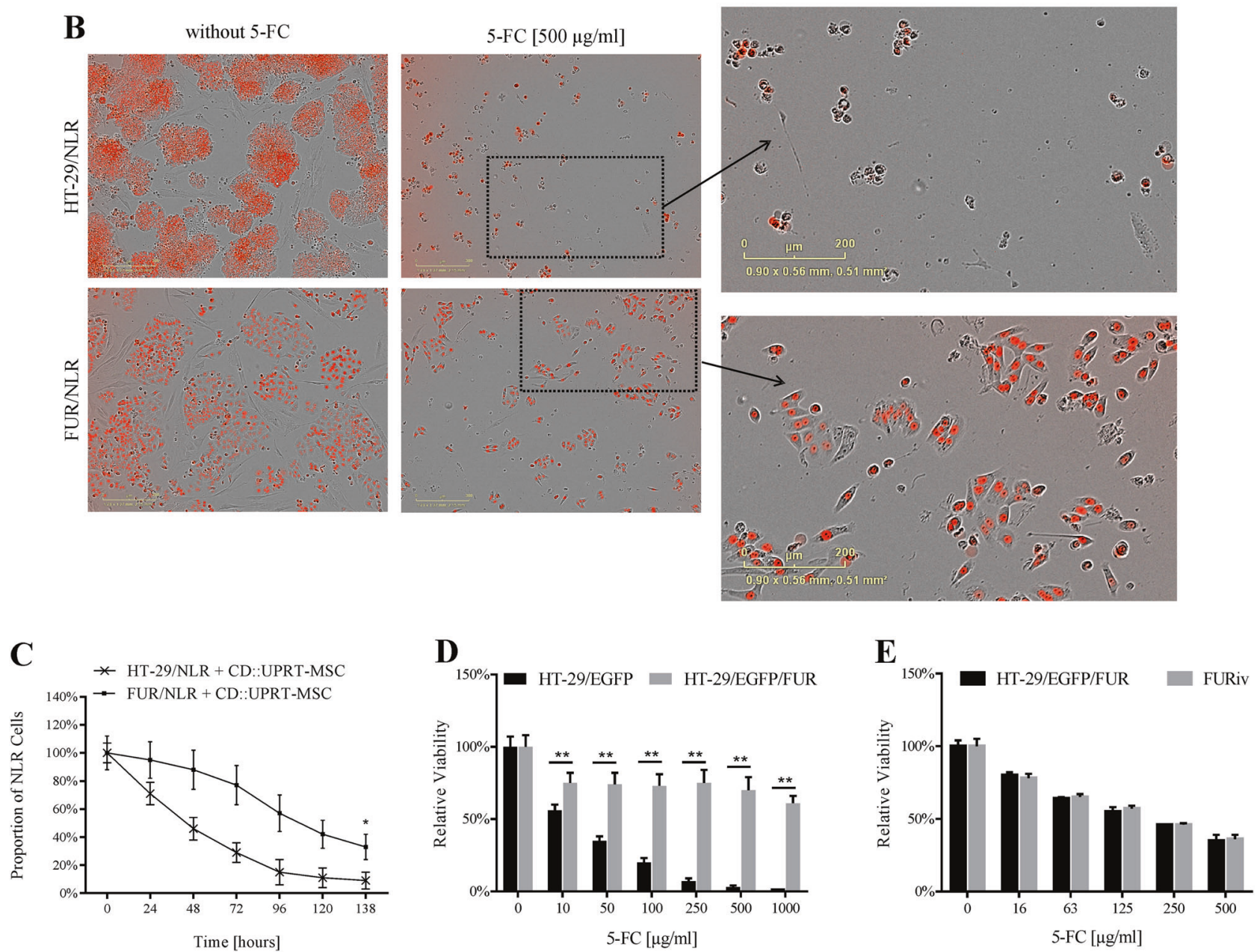

MSC and CD::UPRT-MSC in co-cultures with HT-29/ EGFP/FUR cells, and we confirmed the higher efficacy of fusion enzyme containing UPRT domain (Fig. 3c). In order to identify the metabolites produced by the CD-MSC and CD::UPRT-MSC, we performed the HPLC-MS analysis in cell supernatants. We confirmed more efficient formation and release of 5-FU from engineered MSC transduced with fusion $C D:: U P R T$ gene in comparison to CD-MSC (Fig. 3d), which is in consistence with the finding that
CD::UPRT-MSC exerted although limited but still higher bystander effect on the chemoresistant cells.

In order to examine the potential of the CD::UPRT-MSC to sensitize the chemoresistant cells to 5-FU, we cocultivated CD::UPRT-MSC with HT-29/EGFP/FUR cells. We examined whether the conversion of the 5-FU to toxic metabolites in CD::UPRT-MSC would lead to higher cytotoxic bystander killing of otherwise highly chemoresistant tumor cells. Direct enumeration of the tumor cells in 
Fig. 2 Chemoresistant derivative exhibit limited sensitivity to $\mathrm{CD}$ :: UPRT-MSC/5-FC regimen. The resistance increases with number of passages. The efficacy of the GDEPT was evaluated by direct coculture of the tumor cells and therapeutic CD::UPRT-MSC at a ratio of 5:1 for 6 days after the addition of 5-FC concentration gradient, and the relative luminescence corresponding to the viability was evaluated. Luminescence in co-cultures without 5 -FC was set to $100 \%$ by default (a, d, e). a CD::UPRT-MSC/5-FC did not exert significant cytotoxic effect on chemoresistant cells HT-29/EGFP/FUR when compared to the parental HT-29/EGFP cells. Chemoresistant cells in "low" passages are 43-fold more resistant to CD::UPRT-MSC/5-FC than parental counterparts. The higher passage of cells (stated as middle, high), the higher chemoresistance as shown by counted IC50 values. Values were expressed as means of triplicates \pm SD. Data were statistically analyzed by parametric ANOVA test with Bonferroni's or Tamhanes's tests for multiple comparisons and non-parametric Kruskal-Wallis test. $* p<0.05 ; * * p<0.01 ; * * * p<0.001$. b The red fluorescent representative images from the IncuCyte $\mathrm{ZOOM}^{\mathrm{TM}}$ kinetic imaging system of the tumor cells stained with NucLight ${ }^{\mathrm{TM}}$ Red in the direct co-culture with CD::UPRT-MSC in the presence of $500 \mu \mathrm{g} / \mathrm{ml}$ of 5-FC for 6 days documented the capability of chemoresistant cells (here referred to as FUR/NLR) to withstand the bystander cytotoxicity exerted by the therapeutic cells. c Kinetic measurements based on counting of the red nuclei of the tumor cells in direct co-cultures with CD::UPRT-MSC (5:1 ratio) and 5-FC (500 $\mu \mathrm{g} / \mathrm{ml})$ demonstrated $67 \%$ reduction in the proportion of chemoresistant tumor cells in comparison to $91 \%$ elimination of parental cells. The number of the NLR cells in the co-culture without 5-FC at a given time point was taken as $100 \%$. Values were expressed as means of sextaplicates \pm SD. Mann-Whitney $U$-test was used for statistical analysis. ${ }^{*} p<0.05$. d The analysis of the 3D aggregate co-cultures 7 days after the 5-FC addition showed $97 \%$ reduction in the HT-29/EGFP viability in comparison to only $30 \%$ reduction in the chemoresistant cells at a concentration of $5-\mathrm{FC}$ of $500 \mu \mathrm{g} / \mathrm{ml}$. Expressed as means of sextaplicates \pm SD. Mann-Whitney $U$-test was used for statistical analysis. ${ }^{*} p<0.01$. e In vivo-derived cells of the HT-29/EGFP/FUR xenograft (referred to as FURiv) retained their resistance even after 5month-long in vivo growth, and subsequent 2-month-long in vitro cultivation without the selection pressure of the 5-FU. The sensitivity to CD::UPRT-MSC/5-FC was exactly the same as for HT-29/EGFP/ FUR cells from which the xenotransplant and subsequent FURiv derivative had been established. Values were expressed as means of quadruplicates \pm SD. ns not significant

the direct co-cultures showed indeed, that the proliferation of the chemoresistant cells was significantly more inhibited upon the 5 -FU treatment at a concentration of 5 and $10 \mu \mathrm{g} / \mathrm{ml}$ in the presence of the CD::UPRT-MSC (Fig. 3e).

In order to reveal the mechanism of resistance to cellmediated GDEPT, we focused on the intracellular metabolism and the enzymatic conversion of 5-FC and 5-FU. We compared the expression of enzymes involved in the metabolism of 5-FC and 5-FU by qPCR, namely thymidylate synthase (TS), thymidine phosphorylase (TP), orotate phosphoribosyl transferase (OPRT), and dihydropyrimidine dehydrogenase (DPD). HT-29/EGFP/FUR cells exert increased messenger RNA level of the TS enzyme along with decreased expression of the TP, OPRT, and DPD (Fig. 4a).

We further investigated the correlation between the expression of these enzymes and the resistance of the HT-
29/EGFP/FUR cells to the 5-FU. The comparison of the sensitivity to raltitrexed monohydrate showed higher resistance of the HT-29/EGFP/FUR cells to this specific TS inhibitor even without the previous exposure of cells. The highest concentration of $100 \mathrm{nM}$ exhibited $86 \%$ viability decrease of the HT-29/EGFP cells while only $46 \%$ of the HT-29/EGFP/FUR cells. This result indicates that along with the resistance to the 5-FU, the resistance to raltitrexed has developed in the HT-29/EGFP/FUR cells. Thus, upregulation of the TS correlates with the resistance to the 5-FU (Fig. 4b). To evaluate the possible role of the TP and DPD enzymes in the resistance to the 5-FU, we chose to test their inhibition in the chemonaive HT-29/EGFP cells, which have higher expression of these enzymes compared to HT29/EGFP/FUR. The TP inhibitor TPI at non-toxic concentration of $1.5 \mathrm{ng} / \mathrm{ml}$ significantly increased the chemoresistance in the HT-29/EGFP cells at given concentrations of $5-\mathrm{FU}$ of 0.125 and $0.25 \mu \mathrm{g} / \mathrm{ml}$ (Fig. 4c). The DPD inhibitor gimeracil (GIM) at a non-toxic concentration of $0.6 \mathrm{nM}$ also affected the 5-FU chemosensitivity of the HT-29/EGFP cells (Fig. 4d). These data indicate that the downregulation of the TP and DPD enzymes in the chemoresistant cells might contribute to their resistance, because their pharmacological inhibition shifted the sensitive HT-29/EGFP cells toward the resistant phenotype.

To clarify the link between the decreased OPRT expression in the HT-29/EGFP/FUR cells and the 5-FU resistance, we hypothesized, that the direct introduction of the fusion transgene containing UPRT domain could compensate for the OPRT deficiency in the resistant cells. Therefore, the transgene CD::UPRT was introduced into the HT-29/EGFP/FUR cells by retroviral transduction (cells are referred to as the CD::UPRT-FUR), and the efficiency of the standard gene/prodrug-mediated approach CD::UPRT/ 5-FC in the chemoresistant HT-29/EGFP/FUR cells was evaluated. Cell proliferation of the HT-29/EGFP/FUR cells was not inhibited by low non-toxic concentrations of the 5-FC, but the CD::UPRT-FUR cells exhibited $\mathrm{IC}_{50 / 5-\mathrm{FC}}=3.8 \mu \mathrm{g} / \mathrm{ml}$ (2.2-6.5; $r=0.99)$ after 5-day-long treatment indicative of a potent suicide effect of the CD::UPRT/5-FC regimen on the transduced CD::UPRT-FUR cells (Fig. 5a). Transgene CD::UPRT also increased the sensitivity to the 5-FU in the CD::UPRT-FUR cells in comparison to the HT-29/EGFP/ FUR cells with calculated $\mathrm{IC}_{50 / 5-\mathrm{FU}}$ values of $0.6 \mu \mathrm{g} / \mathrm{ml}$ $(0.4-0.8 ; r=0.99)$ and $16.2 \mu \mathrm{g} / \mathrm{ml}(8.7-30.1 ; r=0.96)$, respectively (Fig. 5b). Thus, direct introducing of exogenous CD::UPRT transgene into the tumor cells sensitized cells to 5-FU 27-fold. We also wanted to determine the extent of the potential bystander cytotoxicity in the direct co-culture of the CD::UPRT-FUR and HT-29/EGFP/FUR cells, mimicking the situation, when the transgene would not be expressed in every cell within the tumor. We 
A

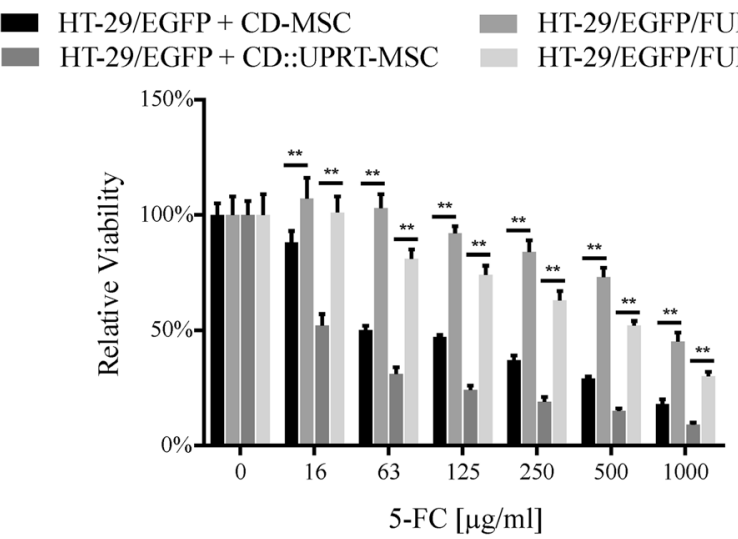

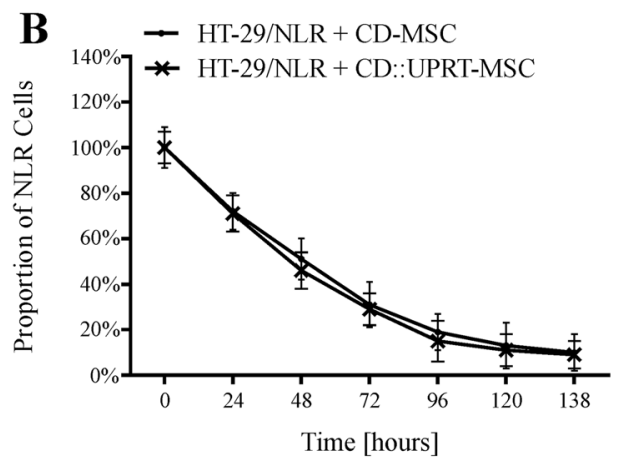

D
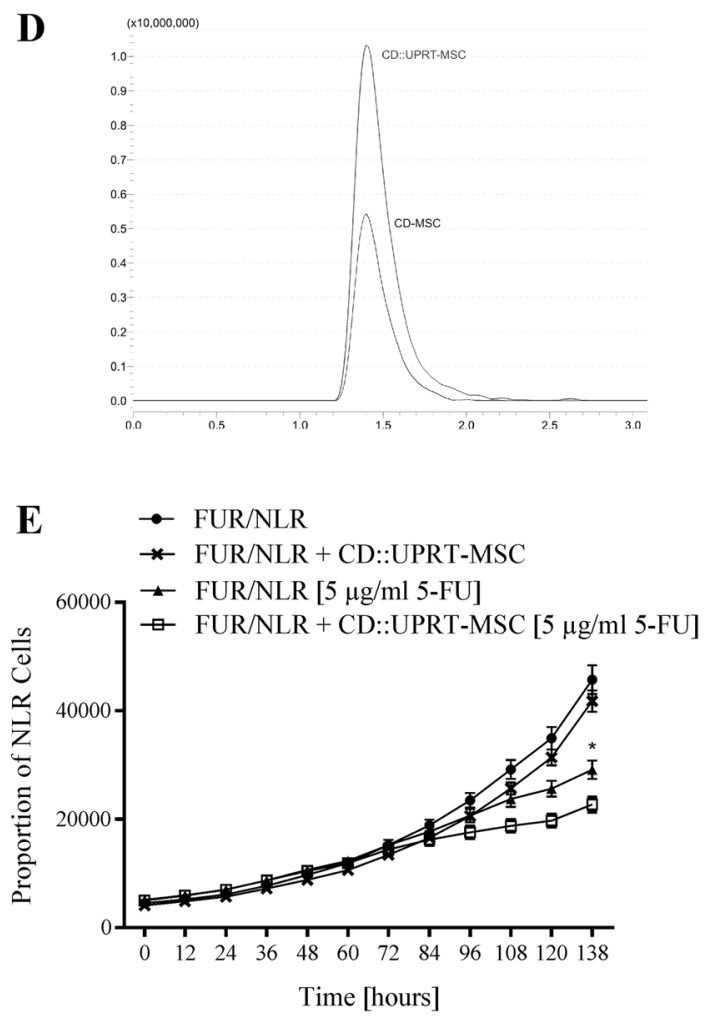

anticipated that the transduced cells undergoing suicide could release the toxic metabolites into their close vicinity thereby inducing the cell death in the neighboring non-
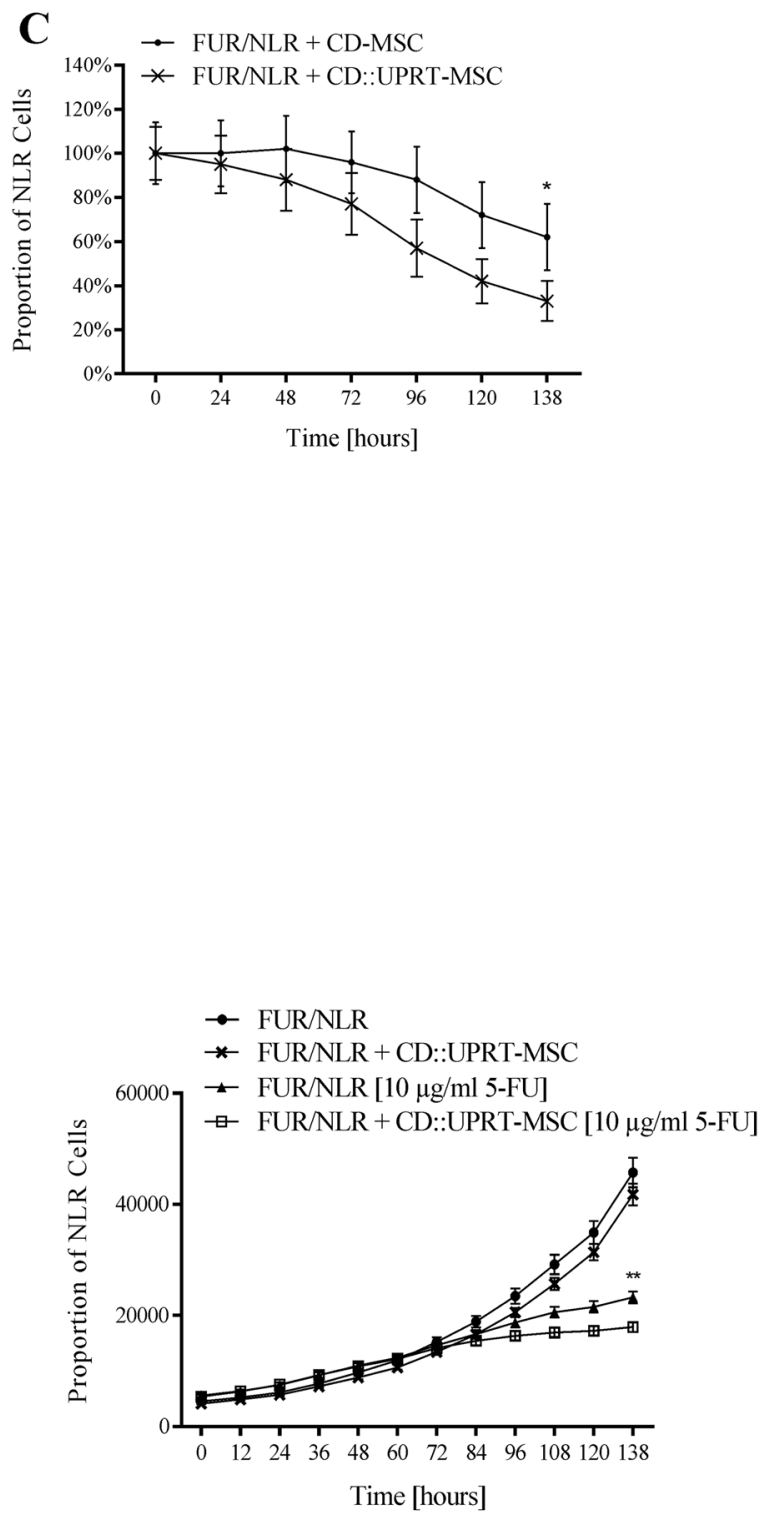

transduced cells. Based on the ratio of the transduced and untransduced cells present in the direct co-culture, the theoretical value of the viability was calculated, representing 
Fig. 3 CD-MSC/5-FC, CD::UPRT-MSC/5-FC, and CD::UPRT-MSC/ 5-FU regimen have limited efficiency in chemoresistant cells. a The HT-29/EGFP and HT-29/EGFP/FUR cells were co-cultivated (5:1 ratio) with either CD-MSC or CD::UPRT-MSC in a concentration gradient of 5-FC, and relative luminescence corresponding to the viability was evaluated on day 6 . The luminescence in co-cultures without the 5 -FC was set to $100 \%$ by default. The bystander cytotoxic effect of both CD-MSC and CD::UPRT-MSC was low in chemoresistant derivative compared to cytotoxicity of therapeutic MSC exerted on the parental cell line. CD-MSC did not exhibit not even $50 \%$ cytotoxicity in the chemoresistant cells when compared to the parental HT-29/EGFP. Values were expressed as means of sextaplicates \pm SD. Mann-Whitney $U$-test was used for statistical analysis. $* * p<0.01$. b Kinetic monitoring and evaluation of a number of red nuclei-stained tumor cells during 6-day-long cocultivation with the therapeutic MSC, and addition of the $5-\mathrm{FC}$ at a concentration of $500 \mu \mathrm{g} / \mathrm{ml}$, showed that regardless of the type of prodrug-converting enzyme used in the treatment regimen of chemonaïve HT-29/EGFP cells, bystander cytotoxicity was not different. The number of NLR cells in the coculture without $5-\mathrm{FC}$ at a given time point was taken as $100 \%$. Expressed as means of sextaplicates \pm SD. c The same experimental setup (as in Fig. 3b) on the chemoresistant HT-29/EGFP/FUR cells showed significant difference in the bystander toxicity between CDMSC or CD::UPRT-MSC treatment. Expressed as means of sextaplicates \pm SD. Mann-Whitney $U$-test was used for statistical analysis. ${ }^{*} p<0.05$. $\mathbf{d}$ The higher efficiency of formation and release of the 5-FU from engineered MSC transduced with fusion $C D:: U P R T$ gene in comparison to CD-MSC confirmed by HPLC-MS. e The direct cocultivation of chemoresistant FUR/NLR cells with therapeutic CD:: UPRT-MSC (5:1 ratio) in the presence of the 5-FU at a concentration of 5 or $10 \mu \mathrm{g} / \mathrm{ml}$ led to significantly increased sensitivity of the tumor cells to 5-FU as evaluated at the experimental end point 6 days after the treatment started by direct enumeration of the red nuclei of the tumor cells. Values were expressed as means of sextaplicates \pm SD. Mann-Whitney $U$-test was used for statistical analysis. ${ }^{*} p<0.05$; $* * p<0.01$

the expected viability in the absence of any bystander cytotoxicity. The viability was substantially lower in comparison to the theoretical values, indicative of the bystander cytotoxicity. Thirty-eight percent decrease in the viability was observed in contrast to calculated $13 \%$ in direct coculture of the transduced CD::UPRT-FUR and HT-29/ EGFP/FUR cells mixed at a ratio of 1:6 (14.3\% of transduced cells to $85.8 \%$ of HT-29/EGFP/FUR cells) in the presence of $250 \mu \mathrm{g} / \mathrm{ml}$ of 5 -FC for 5 days. The bystander effect was consistently observed in the co-cultures of various cell ratios (Fig. 5c).

HPLC-MS analysis documented the presence of the free 5-FU in the culture medium from the CD::UPRT-FUR cells cultured in the presence of 5-FC (Fig. 5d). Moreover, the analysis revealed the presence of FUMP (fluorouridine monophosphate) and FUDR (fluorodeoxyuridine), which probably contribute to the bystander cytotoxicity and killing of the chemoresistant cells without transgene introduction as demonstrated in Fig. 5c.

Taken these results together, we confirmed potent antiproliferative suicide and moderate bystander effect of CD:: UPRT/5-FC treatment on target chemoresistant cells derived from colorectal adenocarcinoma referred to as HT29/EGFP/FUR. Our data suggest the potential of the gene therapy approach to circumvent the chemoresistance in the 5-FU refractory colorectal cells by introducing transgene converting either prodrug 5-FC or chemotherapeutic agent 5-FU.

\section{Discussion}

Mesenchymal stromal cells are of great interest for therapeutic use in clinical applications. Gene-directed enzyme/ prodrug therapy using MSC as delivery vehicles has attracted increasing attention. Our laboratory has also previously reported many studies demonstrating the efficiency of therapeutic MSC expressing either HSVtk or CD::UPRT on various types of tumor cell lines. The study comparing different enzyme/prodrug systems demonstrated that yeast CD::UPRT/5-FC is the most effective among all ones tested [23]. It was of our interest to examine the efficacy of GDEPT approach on a model of chemoresistant colorectal cancer cells as such a study has not been done so far. MSC transduced with single cytosine deaminase gene were not efficient to exhibit even 50\%-bystander effect on chemoresistant derivative, which is in conformity with the knowledge that enzymatic activity of fusion protein CD:: UPRT is increased at least 100 -fold over native yeast CD, thanks to UPRT domain that converts 5-FU to 5-FUMP and improve conversion of 5-FU to active metabolites [24]. Also HPLC analysis proved more efficient formation and release of 5-FU in CD::UPRT-MSC over CD-MSC. Interestingly, regardless of the type of prodrug-converting enzyme (CD versus CD::UPRT) used in the treatment regimen of chemonaive HT-29/EGFP cells, bystander cytotoxicity did not differ.

Strong antitumor effect of systemically administered CD::UPRT-MSC in the presence of 5-FC in vivo on a model of HT-29 colorectal carcinoma was demonstrated [11]. On contrary, in this presented first study on cells with acquired chemoresistance, we observed high resistance to this therapeutic regimen. What is more, we showed that the longer cultivation of cells in 5-FU, the higher resistance to CD::UPRT-MSC/5-FC. It was shown that threedimensional cultures serve for better prediction of therapeutic in vivo outcome $[16,25]$ as they represent a situation of the early-stage non-vascularized tumors and better reflect the extent of the pharmacologic intervention in vivo. We proceeded to test the efficacy of CD::UPRT-MSC/5-FC on 3D aggregate model of tumor and therapeutic MSC at a ratio of $5: 1$, and we confirmed decreased sensitivity of chemoresistant cells also in this experimental setting. The ineffective response might be attributed to the duration of cocultivation in 5-FC presence, thus cells in 3D culture 

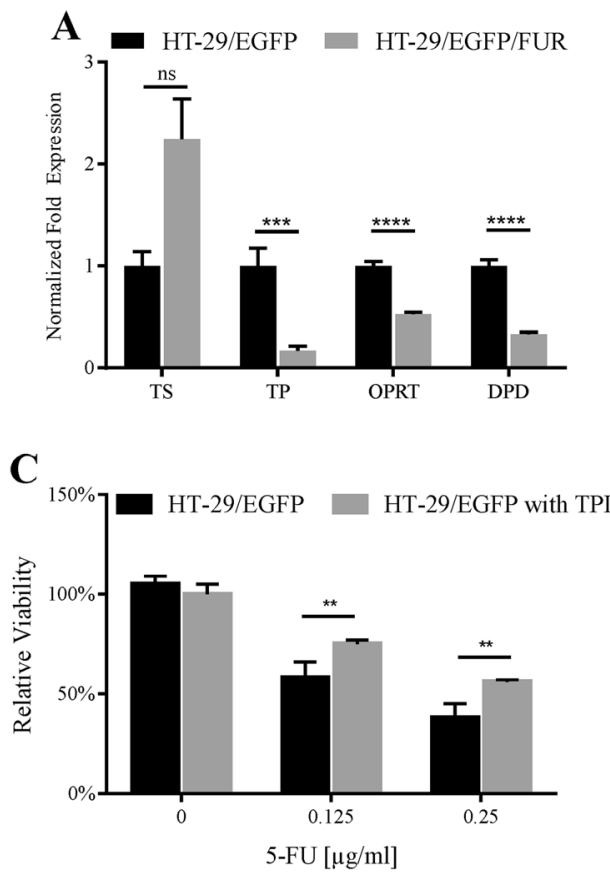

Fig. 4 The resistance to the 5-FU is linked to altered expression of the enzymes playing role in 5-FC and 5-FU metabolism. a Quantitative PCR showed different expression of enzymes involved in 5-FC and 5FU metabolism between parental and HT-29/EGFP/FUR "high" cells. The expression in the HT-29/EGFP cells was set as a reference, GAPDH and HPRT1 served as internal controls. The data are expressed as means of triplicates $\pm \mathrm{SD}$. Student's $t$-test was used for statistical analysis. $* * * p<0.001 ; * * * * p<0.0001$. b The doseresponse curve results show arisen resistance of HT-29/EGFP/FUR cells to specific inhibitor of the TS enzyme raltitrexed even without the previous exposure of the cells to this drug. This resistance correlates with the increased expression of TS in chemoresistant cells. Values

might respond in time-dependent manner. On the other hand, not even the highest concentrations of 5-FC exerted significant decrease in HT-29/EGFP/FUR cell viability, but we observed $97 \%$ reduction in the aggregate volume consisting of HT-29/EGFP.

The efficiency of anti-cancer therapy is dependent also on the expression of enzymes involved in drug metabolism. The orotate phosphoribosyl transferase (OPRT) expression level of HT-29/EGFP/FUR cells was decreased, which would correspond with decreased activation of 5-FU, thus initial conversion of 5-FU to 5-FUMP. It was shown on a model of glioblastoma cell lines [26] that dihydropyrimidine dehydrogenase (DPD) can be used as a biomarker for selecting glioma patients who may benefit from the CDMSC/5-FC therapy. Considering the ability of DPD to deplete 5-FU, it is reasonable to expect that DPD-deficient tumors would be more sensitive to this treatment. On the contrary, even though our results showed decreased expression level of this enzyme in chemoresistant cells compared to parental counterparts, they were more resistant to treatment by CD::UPRT-MSC/5-FC. Several studies
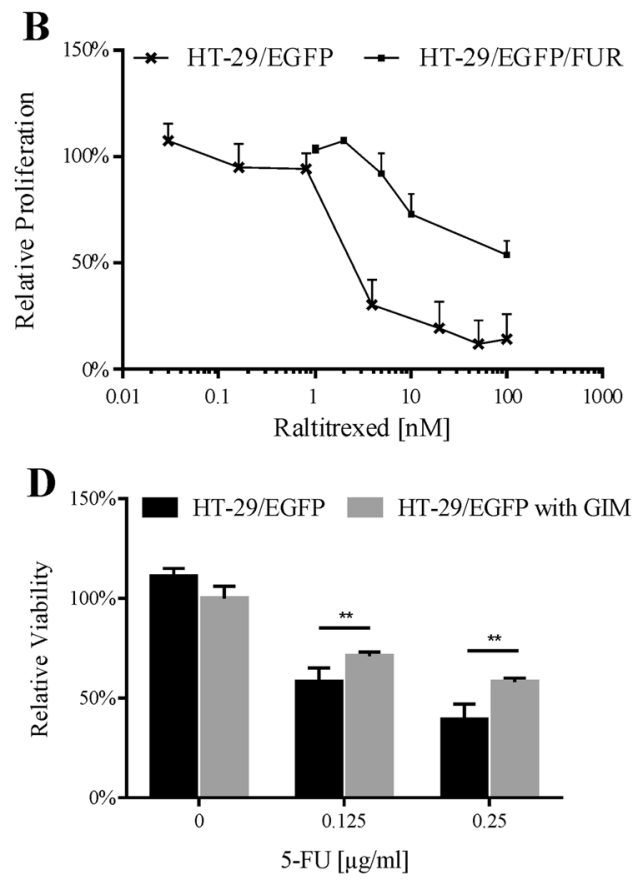

were expressed as means of sextaplicates \pm SD. c The selective inhibition of the TP and (d) DPD enzymes by TPI and GIM, respectively, led to increased 5-FU chemoresistance in the HT-29/EGFP cells. Tumor cells were treated with the 5-FU for 5 days in the presence or absence of specific inhibitors with subsequent viability evaluation. Both TPI and GIM inhibitors significantly reversed 5-FU resistance in HT-29/EGFP cell population. Values were expressed as means of sextaplicates \pm SD. Mann-Whitney $U$-test was used for statistical analysis. $* * p<0.01$. TS thymidylate synthase, TP thymidine phosphorylase, OPRT orotate phosphoribosyl transferase, DPD dihydropyrimidine dehydrogenase, ns not significant

have demonstrated non-significant association of DPD expression with response to 5-FU treatment in colorectal cancer, and the predictive role of DPD level is contentious [27]. Downregulation of thymidine phosphatase (TP), an enzyme converting 5-FU to 5-fluorodeoxyuridine subsequently converted to active metabolite 5-FdUMP, might confer the resistance to 5-FU as a result of lower 5-FdUMP levels. Overexpression of thymidylate synthase (TS), a key determinant of 5-FU sensitivity, was proved to result in development of fluoropyrimidine resistance [28] and prediction of poor response to 5-FU-based chemotherapy [29] which is in accordance with our results. Our data showed that the expression levels of the TS, TP, OPRT, and DPD genes might be connected to the 5-FU resistance of the HT29/EGFP/FUR cells. The role of the TP and DPD enzyme downregulation in decreased sensitivity of HT-29/EGFP/ FUR cells to 5-FU was illustrated by pharmacological inhibition using specific inhibitors TPI and gimeracil, respectively, which inceased the 5-FU resistance in chemonaïve HT-29 cells even within few days. Acquired resistance of the derived cells to the raltitrexed, TS 
A

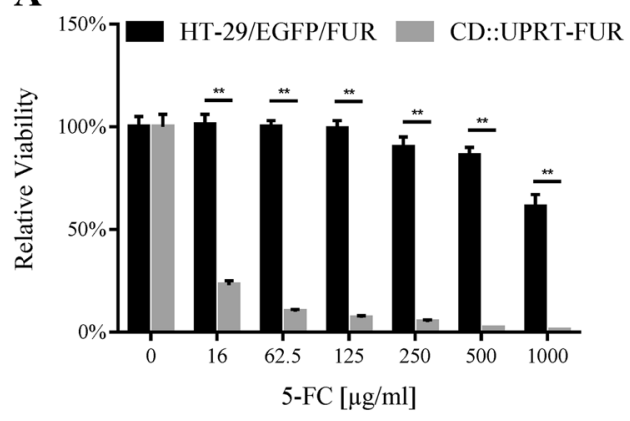

B

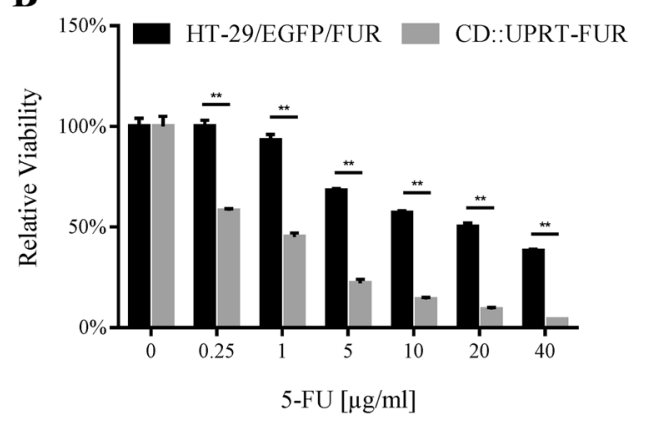

C

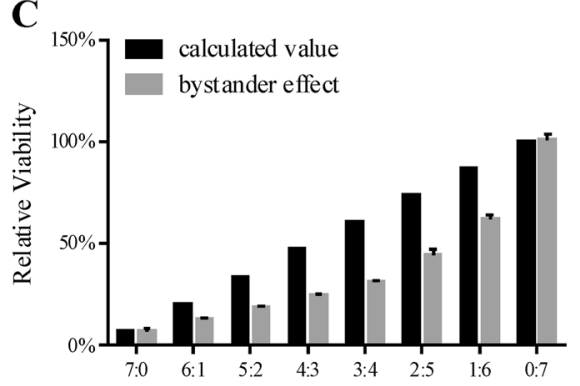

ratio CD::UPRT-FUR : HT-29/EGFP/FUR
D

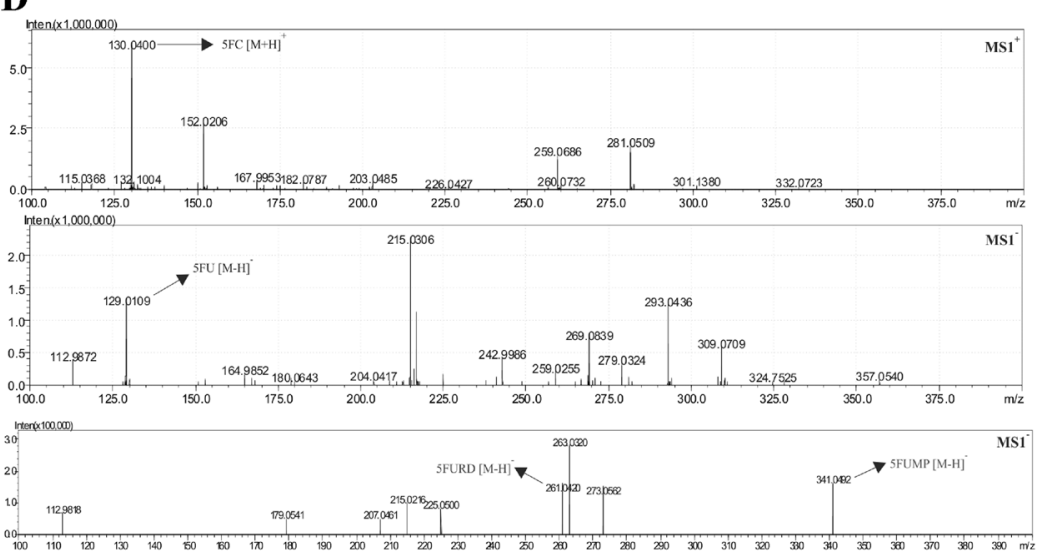

Fig. 5 The insertion of exogenous CD::UPRT transgene into chemoresistant tumor cells leads to extensive suicide effect of otherwise resilient cells. a The cells expressing CD::UPRT (referred to as CD:: UPRT-FUR) were highly sensitive to the prodrug 5-FC as evaluated by the viability luminescence assay 5 days after the treatment started. Non-toxic concentration of $62.5 \mu \mathrm{g} / \mathrm{ml} 5$-FC exerts $90 \%$ cell population reduction of CD::UPRT-FUR in comparison to no effect in HT29/EGFP/FUR cells, thus confirmed potent suicide effect. Values were expressed as means of sextaplicates $\pm \mathrm{SD}$. Mann-Whitney $U$-test was used for statistical analysis. ${ }^{* *} p<0.01$. b The same viability evaluation was used to determine the significantly changed sensitivity of CD::UPRT-FUR cells to the treatment with 5-FU. Calculated IC50 values detected 27 -fold reverted resistance. Values were expressed as means of sextaplicates $\pm \mathrm{SD}$. Mann-Whitney $U$-test was used for

inhibitor, correlates with the TS overexpression, thus pharmacological inhibition in the HT-29/EGFP/FUR cells would not prove efficient. Even though the monotherapy by raltitrexed is sometimes suggested for the patients with advanced colorectal cancer refractory to the 5-FU [30], our data show that the resistance to 5-FU was associated with the cross-resistance to this drug as well. Decreased OPRT and increased TS levels connected to the 5-FU resistance on a model of gastric cancer cell line were demonstrated [31]. We showed that the decreased OPRT expression potentially leading to inefficient 5-FU metabolic conversion might be partially compensated by the co-culture of the tumor cells with the MSC expressing CD::UPRT. The conversion of the 5-FU to toxic metabolites was catalyzed by the product of the $C D:: U P R T$ gene, and led to higher cytotoxic bystander killing of otherwise highly chemoresistant tumor cells. In statistical analysis. $* * p<0.01$. c The obvious bystander cytotoxic effect was confirmed by direct co-culture of HT-29/EGFP/FUR cells mixed with CD::UPRT-FUR at different ratios (to final cell number of 3500 per well in 96-well plates) treated with $250 \mu \mathrm{g} / \mathrm{ml} \mathrm{5-FC} \mathrm{for}$ 5 days. The viability evaluation at the experimental end point showed $38 \%$ viability decrease in the presence of $14.3 \%$ of CD::UPRT-FUR cells. Calculated value stands for calculated viability in the absence of bystander effect if only suicide effect was present. Viability of cells without 5-FC prodrug was set as $100 \%$. Values were expressed as means of sextaplicates \pm SD. d HPLC-MS analysis of metabolites in cell culture supernatant from the HT-29/EGFP/FUR cells retrovirally transduced with CD::UPRT demonstrated that they are capable of synthesis of 5-FU, FUDR, and FUMP

summary, it was demonstrated that the response to $5-\mathrm{FU}$ is based on mutual ratio of enzymes included in its metabolism [32].

To sum it up, in the presented study, we showed that acquired resistance of the HT-29 colorectal carcinoma cells to the 5-FU is associated with alterations in multiple enzymes involved in 5-FU metabolism, and goes along with limited efficiency of the cell-directed enzyme/prodrug treatment. Similarly to all other treatments also, GDEPT mediated by MSC seems to be limited. We proved that the chemoresistance impairs the efficacy of the gene therapy mediated by the MSC expressing prodrug-converting genes. Although the gene therapy is still an experimental treatment approach, first clinical studies employing genetically engineered MSC were initiated [33, 34]. We assume that the possibility of decreased efficacy of the therapeutic system at 
5-FU-treated patients should be taken into consideration at definition of clinical studies' inclusion criteria. On the other hand, the introduction of exogenous CD::UPRT directly into the chemoresistant cells causes significant tumor cells' killing while using non-toxic concentration of 5-FC even better than using toxic drug 5-FU. Thus, based on our results, we propose that instead of using of high toxic concentrations of 5-FU, it would be needed to treat refractory patients by maximal non-toxic concentration of 5-FC along with insertion of CD::UPRT exogene into chemoresistant cells at the same time. As the currently recommended 5-FC dosing regimen yields steady-state maximum plasma concentrations of $60-80 \mu \mathrm{g} / \mathrm{ml}$ [35], the gene therapy protocol CD::UPRT/5-FC seems to fit for the elimination of chemoresistant cells derived from colorectal carcinoma and potentially other 5-FU resistant tumors.

Acknowledgements We thank M. Bohac for providing material for AT-MSC isolation, R. Nencka for providing the TPI inhibitor, B. Smolkova for help with statystical analysis, M. Dubrovcakova, and V. Frivalska for the excellent technical assistance.

Funding This study was supported by the Slovak Research and Development Agency under the contracts APVV-0052-12, APVV0583-11 within the frame of VVCE-0070-07, APVV-15-0697, APVV16-0178, and VEGA grants 02/0178/17, 02/0087/15. The experiments mentioned in this study were enabled with the kind help and the financial support from the Cancer Research Foundation and League against Cancer of Slovak Republic.

\section{Compliance with ethical standards}

Conflict of interest The authors declare that they have no conflict of interest.

\section{References}

1. Kucerova L, Altanerova V, Matuskova M, Tyciakova S, Altaner C. Adipose tissue-derived human mesenchymal stem cells mediated prodrug cancer gene therapy. Cancer Res. 2007;67:6304-13.

2. Bexell D, Scheding S, Bengzon J. Toward brain tumor gene therapy using multipotent mesenchymal stromal cell vectors. Mol Ther. 2010;18:1067-75.

3. Mirzaei H, Sahebkar A, Avan A, Jaafari MR, Salehi R, Salehi H, et al. Application of mesenchymal stem cells in melanoma: a potential therapeutic strategy for delivery of targeted agents. Curr Med Chem. 2016;23:455-63.

4. Cavarretta IT, Altanerova V, Matuskova M, Kucerova L, Culig Z, Altaner C. Adipose tissue-derived mesenchymal stem cells expressing prodrug-converting enzyme inhibit human prostate tumor growth. Mol Ther. 2010;18:223-31.

5. Altaner C, Altanerova V, Cihova M, Ondicova K, Rychly B, Baciak L, et al. Complete regression of glioblastoma by mesenchymal stem cells mediated prodrug gene therapy simulating clinical therapeutic scenario. Int J Cancer. 2014;134:1458-65.

6. Durinikova E, Kucerova L, Matuskova M. Mesenchymal stromal cells retrovirally transduced with prodrug-converting genes are suitable vehicles for cancer gene therapy. Acta Virol. 2014;58:1-13.
7. Portsmouth D, Hlavaty J, Renner M. Suicide genes for cancer therapy. Mol Asp Med. 2007;28:4-41.

8. Kucerova L, Skolekova S, Demkova L, Bohovic R, Matuskova M. Long-term efficiency of mesenchymal stromal cell-mediated CDMSC/5FC therapy in human melanoma xenograft model. Gene Ther. 2014;21:874-87.

9. Hlavaty J, Hlubinova K, Altanerova V, Liska J, Altaner C. Treatment of rat gliomas with recombinant retrovirus harboring Herpes simplex virus thymidine kinase suicide gene. Neoplasma. 1997;44:342-7.

10. Kucerova L, Matuskova M, Hlubinova K, Altanerova V, Altaner C. Tumor cell behaviour modulation by mesenchymal stromal cells. Mol Cancer. 2010;9:129.

11. Kucerova L, Altanerova V, Matuskova M, Tyciakova S, Altaner C. Adipose tissue-derived human mesenchymal stem cells mediated prodrug cancer gene therapy. Cancer Res. 2007;67:6304-13.

12. Kucerova L, Matuskova M, Pastorakova A, Tyciakova S, Jakubikova J, Bohovic R, et al. Cytosine deaminase expressing human mesenchymal stem cells mediated tumour regression in melanoma bearing mice. J Gene Med. 2008;10:1071-82.

13. Kucerova L, Matuskova M, Hlubinova K, Bohovic R, Feketeova L, Janega $\mathrm{P}$, et al. Bystander cytotoxicity in human medullary thyroid carcinoma cells mediated by fusion yeast cytosine deaminase and 5-fluorocytosine. Cancer Lett. 2011;311:101-12.

14. Altanerova V, Cihova M, Babic M, Rychly B, Ondicova K, Mravec B, et al. Human adipose tissue-derived mesenchymal stem cells expressing yeast cytosine deaminase::uracil phosphoribosyl transferase inhibit intracerebral rat glioblastoma. Int $\mathrm{J}$ Cancer. 2012;130:2455-63.

15. Abrate A, Buono R, Canu T, Esposito A, Del Maschio A, Luciano $\mathrm{R}$, et al. Mesenchymal stem cells expressing therapeutic genes induce autochthonous prostate tumour regression. Eur J Cancer. 2014;50:2478-88.

16. Toro L, Bohovic R, Matuskova M, Smolkova B, Kucerova L. Metastatic ovarian cancer can be efficiently treated by genetically modified mesenchymal stromal cells. Stem Cells Dev. 2016;25:1640-51.

17. Matuskova M, Baranovicova L, Kozovska Z, Durinikova E, Pastorakova A, Hunakova L, et al. Intrinsic properties of tumour cells have a key impact on the bystander effect mediated by genetically engineered mesenchymal stromal cells. J Gene Med. 2012;14:776-87.

18. Kucerova L, Durinikova E, Toro L, Cihova M, Miklikova S, Poturnajova M, et al. Targeted antitumor therapy mediated by prodrug-activating mesenchymal stromal cells. Cancer Lett. 2017;408:1-9.

19. Matuskova M, Kozovska Z, Toro L, Durinikova E, Tyciakova S, Cierna Z, et al. Combined enzyme/prodrug treatment by genetically engineered AT-MSC exerts synergy and inhibits growth of MDA-MB-231 induced lung metastases. J Exp Clin Cancer Res. 2015;34:33.

20. Dallas NA, Xia L, Fan F, Gray MJ, Gaur P, van Buren G 2nd, et al. Chemoresistant colorectal cancer cells, the cancer stem cell phenotype, and increased sensitivity to insulin-like growth factor-I receptor inhibition. Cancer Res. 2009;69:1951-7.

21. Matuskova M, Hlubinova K, Pastorakova A, Hunakova L, Altanerova V, Altaner C, et al. HSV-tk expressing mesenchymal stem cells exert bystander effect on human glioblastoma cells. Cancer Lett. 2010;290:58-67.

22. Bohovic R, Demkova L, Cihova M, Skolekova S, Durinikova E, Toro L, et al. 3D multicellular models reflect the efficiency of MSC-directed enzyme/prodrug treatment. Neoplasma. 2015; 62:521-30.

23. Nouri FS, Wang X, Hatefi A. Genetically engineered theranostic mesenchymal stem cells for the evaluation of the anticancer 
efficacy of enzyme/prodrug systems. J Control Release. 2015;200:179-87.

24. Graepler F, Lemken ML, Wybranietz WA, Schmidt U, Smirnow I, Gross CD, et al. Bifunctional chimeric SuperCD suicide gene -YCD: YUPRT fusion is highly effective in a rat hepatoma model. World J Gastroenterol. 2005;11:6910-9.

25. Jung JH, Kim AA, Chang DY, Park YR, Suh-Kim H, Kim SS. Three-dimensional assessment of bystander effects of mesenchymal stem cells carrying a cytosine deaminase gene on glioma cells. Am J Cancer Res. 2015;5:2686-96.

26. Chung T, Na J, Kim YI, Chang DY, Kim H, Moon HE, et al. Dihydropyrimidine dehydrogenase is a prognostic marker for mesenchymal stem cell-mediated cytosine deaminase gene and 5fluorocytosine prodrug therapy for the treatment of recurrent gliomas. Theranostics. 2016;6:1477-90.

27. Scartozzi M, Maccaroni E, Giampieri R, Pistelli M, Bittoni A, Del Prete $\mathrm{M}$, et al. 5-fluorouracil pharmacogenomics: still rocking after all these years? Pharmacogenomics. 2011;12:251-65.

28. Copur S, Aiba K, Drake JC, Allegra CJ, Chu E. Thymidylate synthase gene amplification in human colon cancer cell lines resistant to 5-fluorouracil. Biochem Pharmacol. 1995;49:1419-26.

29. Johnston PG, Lenz HJ, Leichman CG, Danenberg KD, Allegra CJ, Danenberg PV, et al. Thymidylate synthase gene and protein expression correlate and are associated with response to 5fluorouracil in human colorectal and gastric tumors. Cancer Res. 1995;55:1407-12.
30. Van Cutsem E, Cunningham D, Maroun J, Cervantes A, Glimelius B. Raltitrexed: current clinical status and future directions. Ann Oncol. 2002;13:513-22.

31. Mori R, Futamura M, Tanahashi T, Tanaka Y, Matsuhashi N, Yamaguchi $\mathrm{K}$, et al. 5FU resistance caused by reduced fluorodeoxyuridine monophosphate and its reversal using deoxyuridine. Oncol Lett. 2017;14:3162-8.

32. Salonga D, Danenberg KD, Johnson M, Metzger R, Groshen S, Tsao-Wei DD, et al. Colorectal tumors responding to 5fluorouracil have low gene expression levels of dihydropyrimidine dehydrogenase, thymidylate synthase, and thymidine phosphorylase. Clin Cancer Res. 2000;6:1322-7.

33. Niess H, von Einem JC, Thomas MN, Michl M, Angele MK, Huss R, et al. Treatment of advanced gastrointestinal tumors with genetically modified autologous mesenchymal stromal cells (TREAT-ME1): study protocol of a phase I/II clinical trial. BMC Cancer. 2015;15:237.

34. von Einem JC, Peter S, Gunther C, Volk HD, Grutz G, Salat C, et al. Treatment of advanced gastrointestinal cancer with genetically modified autologous mesenchymal stem cells - TREAT-ME1 - a phase I, first in human, first in class trial. Oncotarget. 2017;8:80156-66.

35. Pai MP, Bruce H, Felton LA. Clinical pharmacokinetics of oral controlled-release 5-fluorocytosine. Antimicrob Agents Chemother. 2010;54:1237-41. 